and not of the poison of the snake bite. The bite of the rattlesnake does sometimes prove fatal, but if treated properly, very rarely. Tine tourniquet or ligation of an extremity is always bad. A word as to my method of treatment, and I have treated more than two dozen in the last ten years with no deaths. If there is very recent scarification and sucking of the wound, then I make free incisions and immerse the part in warm water to promote bleeding; then apply gauze wrung out of hot antiseptic solutions on absorbent cotton with moist heat to all the swollen portion; whisky frequently repeated in stimulating doses, no more. Digitalis is sometimes necessary and is very good, when indicated. Free catharsis is produced with calomel and milk diet, or other nutritious articles of easy digestion ordered.

W. Q. Marsh, M.D.

\section{A Question of Medical Ethics.}

Atrantic, Iowa, Nov. 9, 1897.

To the Editor:- The great medical charities of this country are $\mathbf{a}$ credit to the profession and others whose gratuitous ser vices make their existence possible; and no medical man will deny that the good done by these institutions is well-nigh incalculable.

That abuses of the system have been and are constantly being practiced no one will deny, and the periodic complainte from those physicians who live near the large dispensaries are familiar to all who read the current medical journals.

That abuses of medical charities had begun to extend into the country was not suspected by me until lately, when there fell under my observation something that I think needs atten tion from that portion of the profession who believe that quackish methods are not admissible even in the practice of those who are wont to assume that they are exempt from the operation of the time-honored "Code of Ethics." A certain sanitarium whose advertisement can be seen in nearly all the leading medical journals is, as is well known, under the control and guidance of a certain religious organization, and has as its chief medical officer a man who is a prolific writer, and is always prominent on the floor at the meetings of the AMERICAN Medical Association. I find that it is the universal habit of the ministers who preach the gospel as viewed by this sect, to go among the people in their vicinity and solicit cases for this institution, without regard to the circumstances; this is done on the ostensible ground that trained nursing and superior medical skill can be obtained at a far less rate than can be obtained at home. One case that came under observation was that of a man suffering from a large appendiceal abscess, who performed a journey on the cars of over 650 miles and was operated on, making a slow recovery from an intestinal fistula; that he did not rupture the abscess en route and die of peritonitis is due wholly to good luck. Two cases have recently come under my observation in which this same minister ind uced two women to discharge their local physician and repair to this sanitarium for the purpose of having celiotomy done. The chief of the staff of this institution must know of these facts, for he requires the ministers to have the patients ask their attending physicians for a written "diagnosis" of the case before agreeing to admit them; the other binding clause of the bargain is that they pay if they can, and if unable to do this, promise to do so when they can. Patients who are abundantly able to pay are thus taken and worthy men robbed of cases from which they could collect a legitimate fee, that the sanitarium may get the hospital fee, arrangement for which must always be made. If this is legitimate practice of medicine, the country practi. tioners want to know it; and if it is not, let us insist that those who are a party to this sort of thing take their place among the itinerants, and not contaminate our medical meetings with their presence. Yours very fraternally,

Frank W. Porterfield, M.D.

\section{National Medical Education.}

BoIse, IDAHo, Nov. 10, 1897.

To the Editor:- In the article on "National Medical Education" by Dr. Greeley in the JournaL, October 23, someone is quoted as stating that "the effort of the State Society to establish a State Board of Examiners was defeated by the quacks, but this winter will see such a bill passed"; this in reference to Idaho.

I am proud to say that the above quoted prediction was verified on March 12, 1897, and Idaho now has in operation a mixed board of medical examiners, and the act under which this board is operating provides that the person wishing to take up practice in Idaho must possess diploma from a recog. nized school, and pass a satisfactory examination before this board. This provision is met by applicants receiving a marking of at least 75 per cent. on all questions asked. The examination is written, and comprises papers on some fourteen subjects. At the first examination held by the board 50 per cent. failed to pass. This Act of March 12, 1897, is now being attacked in the courts by some who have felt the weight of its provisions, as administered by this Board, and time alone will determine whether the Act as passed by the legislature of 1896-97, will pass muster in the supreme court of the State.

Very truly yours, C. L. SweET, M.D., Secretary Idaho State Board Medical Examiners.

\section{Department of Public Health Bill.}

Chicago, Nov. 10, 1897.

To the Editor:-Will you kindly oblige the undersigned by mailing to my address not less than twenty copies of the Bill looking to the establishment of a Department of Public Heaith, as I propose to do some more missionary work in that direction among our National legislators ere the convening of Congress next month.

The editorial on this subject in the November 6 issue of our Jouinal was most timely, and should elicit renewed interest in the profession every where.

I. trust the enterprising physicians of the United States, to the number of 100,000 , will awake to the necessities of this important piece of legislation, and arouse their Representatives and Senators in both Houses of our Government to renew their interest in this matter for the welfare of this Government and for all her peoples. Very sincerely yours,

Liston H. MontGomery, M.D.

A member from Illinois on the Special Committee of the Amertcan Medical Association on Department of Public Health.

\section{Edema Universalis?}

Chicago, Nov. 13, 1897.

To the Editor:-Med. Dr. Gustavus M. Blech desires to know, in the last number of the JournaL, whether a certain case observed by him is justly called by him "edema univer. salis?" Certainly not. It should be called "edema universale." The meager description offered allows no definite diagnosis, but it seems probable that the edema was due to "sclerema neonatorum." JOSEPH ZEISLER, M.D.

\section{License in Germany?}

Rolla, Mo., Nov. 13, 1897.

To the Editor:--Will some reader of the Journal give information concerning the laws of Germany in regard to American physicians who wish to locate and practice there? What is required of a graduate of American medical schools, in order to obtain license to practice? A READER OF THE JournaL.

Let us have a Department of Public Health! 